\title{
Formação de jovens: ética, cidadania e direitos fundamentais
}

\author{
Isadora Brito de Souza \\ Universidade do Vale do Itajá \\ extensaopaideia@gmail.com
}

\section{Resumo}

O objetivo do projeto consistiu em formar os jovens estudantes do ensino médio das escolas públicas e entidades filantrópicas no município de Itajaí. $\mathrm{O}$ desenvolvimento do projeto ocorreu por meio de palestras em que foram ensinadas aos alunos questões referentes a Ética, Cidadania e Direitos Fundamentais. Essas temáticas foram escolhidas por se entender que elas podem ser aplicadas na vida dos jovens, trazendo-lhes ensinamentos que melhorariam seu convívio e sua inserção na sociedade e lhes permitem conhecer e exercer seus direitos, garantias e deveres. No andamento do projeto, foram utilizados os métodos indutivo e dedutivo para, respectivamente, uma coleta de informações sobre o estilo de vida dos estudantes e de sua formação e análise dos grupos agindo como norteador das soluções. $\mathrm{O}$ projeto já beneficiou 1.938 jovens durante seus três anos de duração, auxiliando-os a compreenderem questões éticas e cidadãs e possibilitando-lhes a inserção em suas vidas de uma consciência da importância da formação e de suas responsabilidades como cidadãos capazes de modificar o futuro do país.

Palavras-chave: Formação. Jovens. Ensino público.

\section{Graduating the young people: ethics, citizenship and fundamental rights}

\begin{abstract}
The project's goal is to graduate young students of the Public Schools and entities of philanthropy in the township of Itajaí. The development of the project occurs through speechs in wich the students are taught about subjects concerning of Ethics, Citizenship and Fundamental Rights. These themes were chosen because is known that they can be applied in young people's life bringing to them teaches that can improve their sociability and their insertion in the society, and that can also permit they know and practice their rights, guarantees and owes. In the development of the project are used the inductive method and the deductive method, the first method is used to collect informations about the lifestyle of the students and their graduating, and the second acts in the analysis of groups acting as guiding solutions. The project has benefited 1.938 young people during its three years, helping
\end{abstract}


them to understand ethical and citizens' issues, enabling them to enter their lives in an conscience of the importance of graduating and of their responsibilities as citizens capable of modifying the country's future.

Keywords: Graduating. Young people. Public teaching.

\section{INTRODUÇÃO}

O Brasil é regido por uma Constituição que garante a todos direitos e deveres, os quais atuam como guias para a condução dos cidadãos e da sociedade. Desse modo, é necessário que todos conheçam os direitos que possuem e a importância deles para a condução de suas vidas.

Entre os motivos que tornam necessária a inserção de temáticas relativas aos direitos e deveres na educação dos adolescentes, encontra-se a necessidade de que desde a infância as pessoas tenham conhecimento acerca dos direitos e garantias que possuem e das obrigações que devem cumprir. Essas informações são fundamentais para que desde cedo as pessoas determinem seu modo de pensar e agir conforme os padrões da sociedade em que se encontram, agindo conforme o que as leis que regem os cidadãos de seu país lhes permitem ou não realizar.

Ao conhecerem desde cedo a sociedade em que estão inseridos, ao conhecerem seus costumes e ao saberem quais comportamentos são aceitáveis ou não para o convívio social, os jovens se desenvolvem tendo maior consciência de que suas ações se refletem no ambiente e nas pessoas com quem eles convivem. Desse modo, ocorre o estímulo do desenvolvimento de um senso de responsabilização, em que cada um passa a compreender que é responsável por suas ações e pelas suas consequências, uma vez que elas podem influenciar no que acontece com a sociedade e com o país em que estão inseridos.

O projeto Formação de Jovens visa à divulgação dos Direitos Fundamentais, da Ética e da Cidadania tendo como objetivo central atuar como um trabalho de formação humana, o qual visa à construção de seres humanos capazes de conduzirem suas vidas de forma 
autônoma tendo em vista o constante progresso e a melhoria dos ambientes e da sociedade em que estão inseridos.

Esse processo de formação atua de modo a inserir na consciência juvenil questões referentes à Ética e à Cidadania, uma vez que elas consistem em pressupostos fundamentais para que, ao aprenderem seus direitos, os jovens não apenas os conheçam, mas, principalmente, estejam aptos para exercê-los em suas vidas. Desse modo, as questões abordadas acerca da Ética e da Cidadania atuam como conhecimentos de preparação para que os jovens se desenvolvam adquirindo habilidades e informações que lhes possibilitem compreender melhor a sociedade em que se encontram e sua importância para o progresso dela.

Essa preocupação com os jovens relaciona-se diretamente a formação do país, pois são eles que em breve serão os responsáveis pelas decisões e atitudes que determinarão o destino do Brasil. Pode-se então afirmar que junto à formação dos jovens também se está decidindo o destino do próprio do país.

Por isso é preciso dedicar maior atenção ao ensino das crianças aos jovens, é alterando a formação deles que se pode alterar a mentalidade que em breve se responsabilizará pelas ações que transformarão o país. É através de projetos que promovam a Cidadania, a Ética, o autoconhecimento e o conhecimento da sociedade que se pode formar pessoas mais preparadas intelectual e emocionalmente, as quais se tornarão capazes de construir uma sociedade mais crítica e consciente.

Esse projeto de formação de jovens se centra em atividades que ensinam aos jovens alguns conceitos centrais para seu desenvolvimento. Os tópicos centrais abordados pelas atividades desenvolvidas são: a Ética, a Cidadania e os Direitos Fundamentais da Pessoa Humana.

A Ética pode ser compreendida como a ciência da conduta humana. Conforme Abbagnano (2006, p. 380), a Ética é a "[...] ciência do fim para o qual a conduta dos homens deve ser orientada e dos meios para atingir tal fim, deduzindo tanto o fim quanto os meios da natureza do homem."

A Ética apresenta então a função de delinear as ações humanas, refletindo, discutindo e estudando as regras de conduta utilizadas no convívio social. Ela pode ser abordada em diversos ramos, tais como a área política, econômica, social, religiosa, profissional, entre outros. A partir disso, pode-se afirmar que a Ética está diretamente relacionada com as ações 
que envolvem a interação pessoal, buscando estabelecer condutas que possibilitem conciliar diferentes culturas e convenções, costumes.

Ao abordar essa temática, deseja-se que os jovens desenvolvam um senso ético e que consigam se orientar segundo um conjunto de valores e comportamentos próprios para o ambiente em que se encontram. Espera-se que, ao aprender o significado da Ética, os jovens passem a tomar atitudes éticas, seja na escola, em seus trabalhos ou em seus ambientes familiares, e que com isso eles estimulem as pessoas com quem convivem a também agirem de maneira ética.

Além da Ética, outro tema de relevância para a formação dos jovens é a Cidadania. Segundo Carvalho (2002, p. 9), ela ocorre de forma plena quando combina a liberdade, a participação e a igualdade, sendo esses elementos tomados como parâmetro para o seu desenvolvimento. A Cidadania também costuma ser relacionada com os direitos civis, políticos e sociais, sendo o cidadão pleno aquele que se torna titular desses três direitos.

É importante que os jovens desde cedo conheçam os direitos que possuem sabendo identificar quando eles são possíveis e necessários para que estejam aptos a dispor de seus direitos. A Cidadania se relaciona diretamente com a vida em sociedade, pois o seu exercício possibilita que os cidadãos conheçam e exerçam seus direitos, auxiliando o convívio social a ocorrer de maneira harmônica.

Desse modo, ser cidadão significa participar da sociedade, conhecer o seu funcionamento e tomar responsabilidade pelo seu desenvolvimento. A Cidadania pode ser praticada por qualquer pessoa e pode consistir em pequenos atos, como manter a cidade limpa e respeitar as pessoas. Desse modo, é importante que os jovens desenvolvam desde cedo uma consciência coletiva, que se responsabilizem pelas próprias atitudes e que promovam os conceitos de Cidadania, influenciando as pessoas a conhecerem e usufruírem seus direitos e a cumprirem os deveres que lhes forem incumbidos.

Ao conciliar a Ética e a Cidadania, pode-se compreender a importância de participar da sociedade e de conhecer os direitos e deveres que cada pessoa possui. Entre os direitos garantidos aos brasileiros pela Constituição, alguns são considerados essenciais: os denominados Direitos Fundamentais da Pessoa Humana. Entre eles encontram-se o direito à vida, à liberdade, à propriedade, à igualdade perante a lei. Segundo Andrade (apud MENDES, 2000. p. 115), os Direitos Fundamentais caracterizam-se como produtos de momentos históricos diversificados, de modo que se torna complexo atribuir-lhes significados 
ou características precisas, no entanto, destaca-se ainda que o "ponto característico que serviria para definir um direito fundamental seria a intenção de explicitar o princípio da dignidade da pessoa humana. Nisso estaria a fundamentabilidade material dos direitos humanos" (2000. p. 115, grifos do autor). Desse modo, os Direitos Fundamentais consistem nos direitos dos seres humanos que são positivados pelo Estado em sua Constituição visando à proteção da dignidade da pessoa humana.

Essas temáticas são a base para o desenvolvimento das atividades do projeto de extensão Formação de Jovens, o qual apresenta como escopo essencial a formação pedagógica dos jovens.

Esse projeto foi desenvolvido por ser necessário que desde cedo as pessoas conheçam e exerçam seus Direitos Fundamentais. Assim, torna-se relevante que os jovens recebam uma formação que lhes possibilite compreender a sua importância como cidadãos participantes da construção da sociedade. No decorrer do projeto, os estudantes adquirem e desenvolvem habilidades, atitudes e conhecimentos que os tornam aptos a construir a suas vidas com autonomia em sociedade.

O projeto é desenvolvido junto a jovens, entre 12 e 17 anos, frequentadores do ensino médio das escolas públicas e de entidades filantrópicas no município de Itajaí. Em sua formação é imprescindível que esses alunos obtenham conhecimento acerca dos direitos que possuem e da importância deles para a construção de suas vidas e para o desenvolvimento da vida social, uma vez que todos são agentes atuantes na sociedade e possuem a responsabilidade de auxiliá-la em seu desenvolvimento.

O projeto de extensão em sua proposta abrange não apenas o conhecimento dos conceitos de Ética, Cidadania e Direitos Fundamentais, mas se caracteriza principalmente como um trabalho de formação humana, de modo que apresenta como objetivo central a formação de pessoas capazes de conduzir a própria vida com autonomia. Para a concretização desse objetivo, é preciso que os alunos sejam introduzidos a questões éticas e cidadãs, pois são elas que auxiliarão os estudantes a não apenas conhecerem os Direitos Fundamentais, mas, sobretudo, a exercê-los em suas vidas.

A educação de crianças e jovens deve ser entendida como um elemento determinante para o futuro do país, uma vez que é a partir dos ensinamentos dessas fases que o desenvolvimento das pessoas começa a ser determinado. Desse modo, torna-se importante estimular desde cedo o conhecimento de questões referentes à Cidadania, à Ética, e aos 
Direitos Fundamentais, uma vez que elas podem influenciar na convivência dos homens em sociedade e determinar o seu amadurecimento, podendo causar transformações nos comportamentos e decisões que eles virão a tomar.

Desse modo, figuram como fim do projeto a formação de jovens atuantes na sociedade, que se conheçam e sejam capazes de serem cidadãos que agem de forma ética zelando pelos Direitos Fundamentais e pela organização da vida em sociedade.

\section{MATERIAL E MÉTODOS}

No decorrer do ano de 2010, foram realizadas palestras aos estudantes do ensino médio das escolas públicas e aos frequentadores de entidades filantrópicas no município de Itajaí/SC. Entre as instituições beneficiadas encontram-se a Escola de Ensino Médio Victor Meirelles e a Escola de Ensino Médio Nereu Ramos. Essas palestras foram desenvolvidas por bolsistas e voluntários do Grupo de Pesquisa e Extensão Paidéia, que é um grupo criado dentro do Curso de Direito da Universidade do Vale do Itajaí e cadastrado no CNPq, o qual já completou dez anos de existência, durante os quais já beneficiou não apenas o CEJURPS, mas toda a universidade e parte da comunidade de Itajaí através de seus projetos de extensão.

O projeto do Grupo Paideia tem em vista a formação dos jovens baseando-se na cultura humanista, isto é, em uma proposta que apresenta bases em um modelo cultivado desde a Grécia Antiga, o qual visa ao desenvolvimento do melhor dos homens. Para tal, estimula-se a formação integral das pessoas, valorizando especialmente o desenvolvimento intelectual e existencial dos jovens, para que eles estejam preparados para desenvolverem papéis de liderança na sociedade.

Esses jovens foram os responsáveis pela condução das palestras, as quais foram realizadas com os primeiros, segundos e terceiros anos do ensino médio, de modo que se trabalhasse com jovens que em sua maioria possuíssem entre 12 e 17 anos. As palestras ocorreram semanalmente, tiveram a duração de uma aula (cerca de 45 minutos) e normalmente foram ministradas por dois ou três bolsistas, que abordaram questões referentes à Ética, à Cidadania e aos Direitos Fundamentais.

Entre os temas abordados no decorrer do ano encontram-se: (i) o significado de Ética, Cidadania e Moral, cujos conceitos foram explicados utilizando-se exemplos relativos à vida 
dos jovens, para isso, abordou-se a Ética Profissional, Educacional e Familiar, as ações que um bom cidadão deve desempenhar, e as atitudes que podem ser consideradas morais ou imorais; (ii) as habilidades que podem ser necessárias para o convívio em sociedade, demonstrando aos jovens quão importantes podem ser suas atitudes e decisões; (iii) a

importância da oratória e da interpretação, apresentando o quanto elas são necessárias ao estudo, à profissão e às relações interpessoais; (iv) os direitos e deveres dos cidadãos, explanando também aqueles que são exclusivos das crianças e adolescentes e que podem ser encontrados no ECA (Estatuto da Criança e do Adolescente); (v) os princípios constitucionais norteadores da República Federativa do Brasil, destacando aos estudantes a relevância de compreenderem desde cedo o que é ser um cidadão e como ocorre o funcionamento do Estado do qual fazem parte; (vi) o funcionamento do sistema eleitoral, pois, em 2010, ocorreram eleições para os mais altos postos da república, situação que despertara o interesse dos jovens para questionamentos acerca do modo como o país era conduzido e de como seus poderes são distribuídos; e (vii) a orientação vocacional, a qual visa estimular os jovens a pensarem sobre o futuro e a compreenderem a necessidade de desenvolverem algumas habilidades para que consigam se inserir no mercado de trabalho.

A formação dos jovens abrangeu diversas áreas, portanto foi elaborada uma vasta quantidade de atividades. Para o desenvolvimento intelectual dos jovens, foram utilizadas tarefas que incluíam a leitura e interpretação de textos e a resposta a questionários; para o estímulo cultural e artístico, foram desenvolvidas a realização de desenhos e a apresentação de peças de teatro; e, para a estimulação de habilidades como a atenção, o respeito e a criatividade, foram organizadas atividades como a preparação de debates, a elaboração de trabalhos em equipe e a apresentação de aulas explicativas.

O encerramento das palestras ocorreu por meio de dinâmicas, método que estimula os jovens a prestarem atenção quando os bolsistas e voluntários estão explanando o tema e que permite que os estudantes não atuem apenas como expectadores, mas que também se envolvam nas atividades. Assim, as dinâmicas apresentaram-se como uma maneira diferenciada e eficiente de aprendizado. Depois da realização das dinâmicas, realizou-se um resumo do tema que foi abordado no dia e apresentaram-se algumas indicações de como essa temática pode ser inserida no cotidiano dos estudantes. Com isso, estimularam-se os alunos a 
compreenderem os pontos centrais do assunto abordado e a porem em prática o que aprenderam.

\section{RESULTADOS E ANÁLISE}

O projeto Formação de Jovens desenvolvido pelo Grupo Paideia tem-se ampliado nos últimos anos. Em 2008, 111 jovens foram atendidos, no ano seguinte, 397 jovens foram beneficiados, e, em 2010, estima-se que o projeto tenha abrangido 1.430 jovens.

No desenvolvimento das palestras, foi transmitido aos jovens um entendimento maior acerca de suas vidas, uma vez que lhes foi ensinado: (i) como agir de maneira ética; (ii) como lidar com a vida em sociedade; (iii) a importância de cada um para o desenvolvimento do país, conscientizando-os de que a atitude de cada pessoa é responsável pelo progresso do país; e (iv) a compreensão de que, ao conhecerem questões a respeito da Ética e Cidadania e dos Direitos Fundamentais, os alunos podem reconhecer a relevância que elas têm para o desenvolvimento da vida dos homens e da sociedade, e, com isso, tornarem-se aptos a exercerem seus direitos agindo como cidadãos e tendo uma consciência ética que lhes permita agir tendo em vista o progresso de sua nação.

Através dos conhecimentos passados aos estudantes, também foram sendo desenvolvidas algumas atitudes e habilidades, tais como o respeito às diferenças, o trabalho em grupos, a leitura e interpretação, características essas que podem auxiliar os jovens em sua vida pessoal, em sua integração ao mercado de trabalho e em todas as suas ações.

Para o desenvolvimento das atividades, observou-se primeiro a condição dos jovens, partindo da premissa de que os estudantes estão em processo de formação, de modo que é preciso torná-los conscientes da situação social em que se encontram e a partir disso estimulálos a desenvolverem suas capacidades de ação e de decisão.

Através das atividades procurou-se averiguar a realidade em que cada grupo vive. Isso se tornou relevante por facilitar aos jovens a inserção dos ensinamentos em suas vidas, de modo que ao aplicá-los compreendam melhor o real significado da Ética e da Cidadania.

O projeto destinou-se especificamente a escolas de ensino público, porque elas apresentam um sistema de ensino falho em alguns aspectos. O projeto foi, portanto, uma maneira de tentar minimizar esses problemas levando conhecimentos aos jovens, dando-lhes a oportunidade de se conhecerem melhor e terem acesso a informações que lhes possibilitem 
tornarem-se cidadãos conscientes do que acontece em seu país e capazes de influenciar no progresso dele.

Os temas foram abordados com o intuito de que os jovens sintam que a Cidadania, a Ética e o Direito fazem parte de sua realidade, de modo que cada estudante saiba que é um cidadão e se sinta como parte integrante da sociedade, compreendendo seus direitos e deveres.

Os jovens foram envolvidos por temáticas que a princípio não sabiam o que eram, mas que depois tiveram a certeza de que estavam relacionadas com seu próprio cotidiano. Conforme os estudantes aprendiam, desenvolviam o interesse de conhecer melhor a si mesmos, a sociedade e o país a que pertencem.

O projeto proporcionou aos jovens o desenvolvimento de habilidades e competências como respeito às diferenças, aprimoramento da linguagem, melhora na capacidade de formar hipóteses e análises, desenvolvimento crítico, estímulo da criatividade, aprendizado acerca do convívio em grupo, entre outros.

Com o desenvolvimento desse projeto, os jovens passaram a perceber que acadêmicos podem influenciar a comunidade, que as escolhas são importantes, que sempre é possível auxiliar os outros em seu trajeto de aprimoramento e que, assim como os acadêmicos da UNIVALI se dispuseram a atuar nesse projeto de extensão em benefício dos jovens, eles também podem se envolver em causas sociais, podendo também contribuir para o desenvolvimento da sociedade.

As consequências desse projeto de formação de jovens visam que eles alterem seu ambiente escolar e familiar, que percorram um caminho de autoconhecimento, que estejam em constante progresso, que desenvolvam características para sua inserção no mercado de trabalho e que tenham conhecimentos que lhes possibilitem agir como bons cidadãos visando à melhoria da sociedade e da nação.

Os beneficiados, no entanto, não foram apenas os estudantes do ensino médio de escolas públicas e entidades filantrópicas, bolsistas e voluntários também receberam grande aprendizado durante a concretização desse projeto.

Os bolsistas primeiramente elaboraram o projeto e agiram de modo que ele pudesse ser efetivamente concretizado. Para tal foi necessário entrar em contato com a secretária das escolas, conversar com diretores, coordenadores e professores, mostrando a eles os benefícios que o projeto poderia apresentar para as instituições. Essa primeira tarefa fez com que os 
bolsistas desenvolvessem responsabilidade, praticassem a oratória e a capacidade de persuasão.

Para a elaboração das atividades, foram necessárias a organização do calendário de eventos, a combinação dos pares responsáveis por cada palestra e a divisão dos temas, tarefas que exigiram dos participantes organização, disponibilidade, capacidade de trabalhar em equipe e criatividade, características que foram sendo aprimoradas junto ao desenvolvimento das atividades.

Entre as atividades desenvolvidas encontra-se a apresentação de peças teatrais, as quais envolveram os participantes desde a decisão das peças que seriam encenadas (uma peça grega baseada no mito de Eros e Psique e a peça teatral Dédalo) ao desenvolvimento dos roteiros, a definição dos atores, a elaboração e a confecção do cenário e dos figurinos, a realização de ensaios e a apresentação ao público. Essa atividade permitiu que os participantes que atuaram se conhecessem melhor, descobrissem suas dificuldades e, através de conselhos e ensaios, superassem desafios. Além disso, as apresentações teatrais também proporcionaram o trabalho em equipe e demonstraram uma capacidade de transmitir conhecimentos referentes a diferentes áreas de um modo dinâmico que entreteve os jovens proporcionando-lhes uma experiência de aprendizado diversificada.

Esse projeto possibilitou aos acadêmicos uma oportunidade de desenvolvimento pessoal, pois, ao participarem nas escolas, além do aprimoramento proveniente das habilidades adquiridas, as pessoas também são preenchidas por um sentido de completude e realização por saberem que com esse projeto, além de se desenvolverem, elas também estão auxiliando outros jovens a se conhecerem, a descobrirem que têm muitas qualidades, que podem estar em constante progresso e que são importantes para a sociedade e para a melhora do país.

O projeto do grupo Paidéia foi criado com base em uma proposta humanista, e, por isso, procurou o desenvolvimento integral do indivíduo. Ao envolverem-se nas atividades do projeto de extensão Formação de Jovens, os bolsistas e voluntários desenvolveram-se nas dimensões intelectual, cultural, comportamental e social.

Além do benefício proporcionado aos jovens estudantes e aos acadêmicos, esse projeto demonstrou uma preocupação com o desenvolvimento de projetos que tenham em vista benefícios para a comunidade. 


\section{CONSIDERAÇÕES FINAIS}

O projeto de extensão visa à formação de jovens estudantes do ensino médio de escolas públicas e entidades filantrópicas no município de Itajaí/SC, apresentando como temáticas centrais a Ética, a Cidadania e os Direitos Fundamentais.

O projeto visa à formação de jovens, para que eles se desenvolvam tornando-se cidadãos capazes de agir de modo ético, tendo conhecimento acerca de seus direitos e podendo, a partir disso, tomar suas decisões de modo consciente tendo em vista o progresso da sociedade e do país.

O projeto já beneficiou inúmeros jovens orientando-os quanto à relevância de seus comportamentos, do conhecimento de seus direitos e deveres e do autoconhecimento para o próprio desenvolvimento e para melhoria dos ambientes em que eles se encontram, tais como a escola, a família e o bairro.

Os jovens participantes desse projeto foram envolvidos em atividades que lhes proporcionaram o aprimoramento de habilidades e lhes ensinaram a importância das suas ações e decisões, uma vez que serão eles os futuros responsáveis pelo destino do Brasil.

O desenvolvimento do projeto de extensão do Grupo Paideia beneficiou, através da Escola de Ensino Médio Victor Meirelles e da Escola de Ensino Médio Nereu Ramos, tanto os acadêmicos da Universidade do Vale do Itajaí quanto a própria universidade e a comunidade de Itajaí. 


\section{REFERÊNCIAS}

ABBAGNANO, Nicola. Dicionário de Filosofia. São Paulo: Martins Fontes, 2006.

CARVAlHO, José Murilo de. Cidadania no Brasil: o longo caminho. $3^{\mathrm{a}}$ ed. Rio de Janeiro: Civilização Brasileira, 2002.

JAEGER, Werner Wilhelm. Paidéia: a formação do homem grego. São Paulo: Martins Fontes, 1995.

MENDES, Gilmar. Hermenêutica constitucional e direitos fundamentais. Brasília: Brasília Jurídica, 2000.

MENEGHETTI, Antonio. Fundamentos de Filosofia. São Paulo: Ontopsicologica Editrice, 2005.

MOREIRA, Marco Antônio. Ensino e Aprendizagem: enfoques teóricos. 3 ed. São Paulo: Moraes, 1990.

UNIVALI. Projeto Pedagógico do Curso de Direito da UNIVALI. Itajaí, 2003. 